\title{
Minor Constituents from Phyllosticta sp. and Their \\ Correlation with Epoxydon (Phyllosinol)
}

\author{
Sadao Sakamura, Kensuke Nabeta, Shoichi Yamada \\ and Akitami ICHIHARA. \\ Department of Agricultural Chemistry, Faculty of Agriculture, \\ Hokkaido University, Sapporo
}

Received July 22, 1974

\begin{abstract}
Three new compounds were isolated from Phyllosticta sp. and the structures were elucidated by spectroscopic data. Chemical conversion of epoxydon to these compounds confirmed the stereostructures to be 3,4 and 5 respectively.
\end{abstract}

In the series of studies of metabolites from Phyllosticta sp. we reported the isolation, ${ }^{11}$ biological activities, ${ }^{2)}$ chemical synthesis ${ }^{3)}$ and biosynthesis $^{4)}$ of two main metabolites, epoxydon (phyllosinol 1) and phyllostine (2).<smiles>O=CC1=C[C@@H](O)[C@H]2O[C@H]2C1=O</smiles>

Further examination of the acetone extract from the culture broth of phyllosticta sp. revealed the presence of three minor cyclohexenone derivatives which have now been isolated in a pure state on chromatography, followed by careful crystallization. The structural elucidation of these compounds has been briefly reported. ${ }^{5)}$ The detailed structural and stereochemical studies of three new compounds, 6(S)-chloro-4(R),5(R)-dihydroxy-2-hydroxymethylcyclohex-2-en-1-one (3), 6(R)chloro-4(R), 5(R)-dihydroxy-2-hydroxymethylcyclohex-2-en-1-one (4) and 6(S)-acetoxy-4(R), $5(\mathrm{R})$ - dihydroxy - 2-hydroxymethylcyclohex-2en-1-one (5) are described herein.

Isolation procedure of these compounds are illustrated in Schemes 1 and 2.

The first compound (3), $m p 126^{\circ} \sim 128^{\circ} \mathrm{C}$, $\mathrm{C}_{7} \mathrm{H}_{9} \mathrm{O}_{4} \mathrm{Cl}$ has a UV maximum at $226 \mathrm{~nm}$ ( $\varepsilon 5600)$ indicating the presence of $\alpha, \beta$-unsatu-<smiles>O=C1C(CO)=C[C@H](O)[C@H](O)C1Cl</smiles>

3<smiles>CC(=O)OC1C(=O)C(CO)=C[C@H](O)[C@@H]1O</smiles>

5<smiles>O=C1C(CO)=C[C@H](O)[C@H](O)[C@H]1Cl</smiles>

4

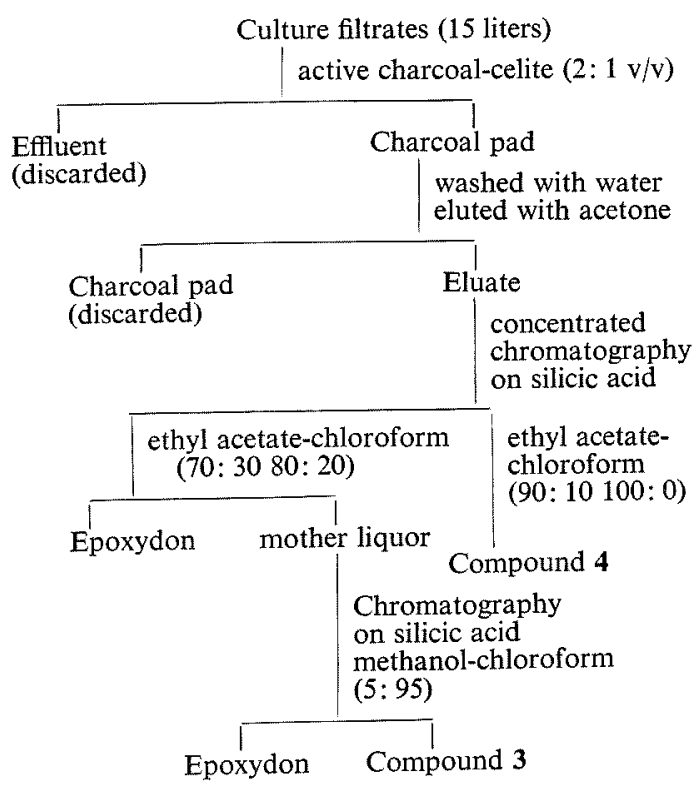

SCHEME 1. 


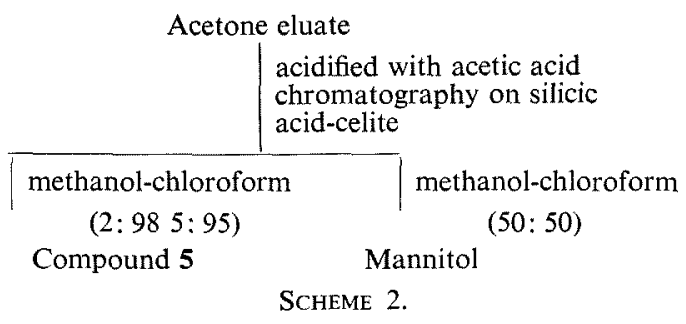

rated ketone, and shows strong $\mathrm{OH}$ absorption at $3250 \mathrm{~cm}^{-1}$ and an $\alpha, \beta$-unsaturated carbonyl band at $1685 \mathrm{~cm}^{-1}$ in the IR spectrum. The PMR spectrum (chart la) reveals the following structural features; a vinylic proton at $\delta 6.91$, allylic $\alpha$-proton to $\mathrm{OH}$ at $\delta 4.73, \alpha$-proton to chlorine at $\delta 4.47(\mathrm{~d}, J=6.8 \mathrm{~Hz}), \alpha$ proton to $\mathrm{OH}$ at $\delta 4.14$ and a hydroxymethyl group at $\delta 4.43$. The position of chlorine atom was determined by the fact that this compound was converted to its epimer 4 , in turn to 3-chloro-2,5-dihydroxybenzyl alcohol. These data indicate that the compound 3 has a structure 6-chloro-2-hydroxymethyl-4,5dihydroxycyclohex-2-en-1-one. A rather large coupling constant of the signal at $\delta 4.47$ indicates that the chlorine atom at C- 6 and the hydroxyl group at $\mathrm{C}-5$ occupy two equatorial positions in the half chair conformation. The stereochemistry including absolute configuration of compound 3 was determined by the correlation with epoxydon whose stereochemistry had been established. Thus, epoxydon was treated with conc. hydrochloric acid in ethanol. The reaction proceeded through stereospecific trans diaxial opening of the epoxide ring to an unstable conformer (a) which was converted to a stable conformer $\mathbf{3}$ as illustrated below.
Therefore, the stereochemistry must be depicted as 3 and designated as $6(\mathrm{~S})$-chloro-4(R),5(R)dihydroxy -2-hydroxymethyl-2-cyclohexen-1one (3).

The second minor compound (4), $\mathrm{mp} 142^{\circ} \sim$ $144^{\circ} \mathrm{C}, \mathrm{C}_{7} \mathrm{H}_{9} \mathrm{O}_{4} \mathrm{Cl}$, is colorless needles, soluble in acetone, ethyl acetate and ethanol but insoluble in chloroform and ether. The compound has a UV maximum at $232 \mathrm{~nm}(\varepsilon 8450)$ indicating the presence of an $\alpha, \beta$-unsaturated ketone. The IR spectrum showed an $\mathrm{OH}$ band at $3300 \mathrm{~cm}^{-1}$ and an $\alpha, \beta$-unsaturated $\mathrm{C}=0$ absorption at $1700 \mathrm{~cm}^{-1}$. The PMR spectrum of 4 (chart $1 \mathrm{~b}$ ) exibited a vinylic proton located to $\beta$-position of $\alpha, \beta$-unsaturated ketone at $\delta 6.77, \alpha$ proton to chlorine atom at $\delta 5.01$, $\alpha$ proton to $\mathrm{C}-4 \mathrm{OH}$ at $\delta 4.78, \alpha$ proton to $\mathrm{C}-5$ $\mathrm{OH}$ at $\delta 4.50$. Broadening of signals in compound 4 might be due to the presence of an equillibrium between two conformers, since spin-decoupling experiments showed still unresolvable signals. This compound is an isomer of compound 3 and the position of the chlorine atom was established by the fact that 4 was easily transformed to 3-chloro-2,5-dihydroxybenzyl alcohol. The compound was correlated with compound 3 through enolization. Thus, compound 3 was treated with aqueous sodium bicarbonate $(10 \%)$ in tetrahydrofuran for $3 \mathrm{~min}$ at $30^{\circ} \mathrm{C}$ to yield compound 4. The stereochemical structure would be 6(R)-chloro-4(R),5(R)-dihydroxy-2-hydroxy methyl-2-cyclohexen-1-one (4).

The third compound (5), $\mathrm{C}_{9} \mathrm{H}_{12} \mathrm{O}_{6}$ is colorless plates. The UV spectrum was characteristic of $\alpha$-substituted $\alpha, \beta$-unsaturated ketone. Two

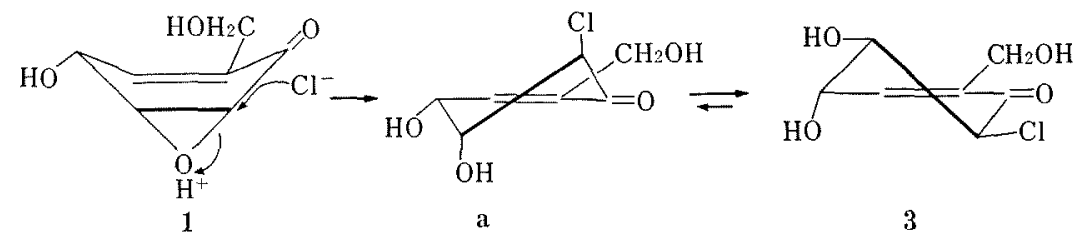

The crystalline product was identical with natural specimen in the IR spectrum and the optical rotation $[\alpha]_{D}=-125^{\circ}$, showed the same sign as that of natural compound $[\alpha]_{\mathrm{D}}=-158^{\circ}$. kinds of carbonyl absorption at $1740 \mathrm{~cm}^{-1}$ (ester) and $1682 \mathrm{~cm}^{-1}$ ( $\alpha, \beta$-unsaturated carbonyl) were observed in the IR spectrum. The PMR spectrum (chart 1c) showed a signal at $\delta 2.10$ 
due to an acetoxy group and the large coupling constant $(J=10.8 \mathrm{~Hz})$ of the signal at $\delta 5.54$ due to $\alpha$-proton to the acetoxy group indicates that the acetoxy group and the vicinal hydroxyl group are equatorially located at C-6 and $\mathrm{C}-5$ respectively in the half chair conformation. Since treatment of epoxydon with boron tri- fluoride etherate in acetic acid gave the compound 5 through diaxial opening of the epoxide, the absolute configuration was designated as 6(S) - acetoxy-4(R),5(R) - dihydroxy-2-hydroxymethyl-2-cyclohexen-1-one (5).

The compound 3 was able to be detected in the ethyl acetate extract of the culture broth

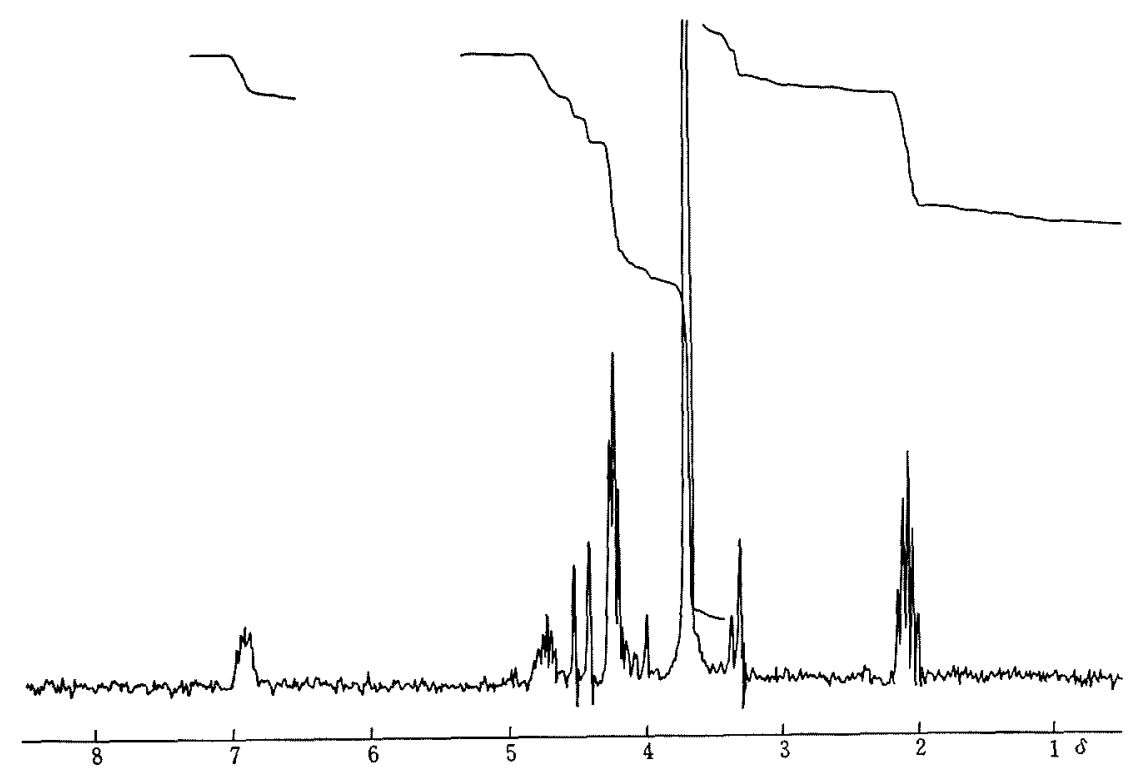

Chart 1a. PMR Spectrum of Compound $3\left(\left(\mathrm{CD}_{3}\right)_{2} \mathrm{CO}+\mathrm{D}_{2} \mathrm{O}\right)$.

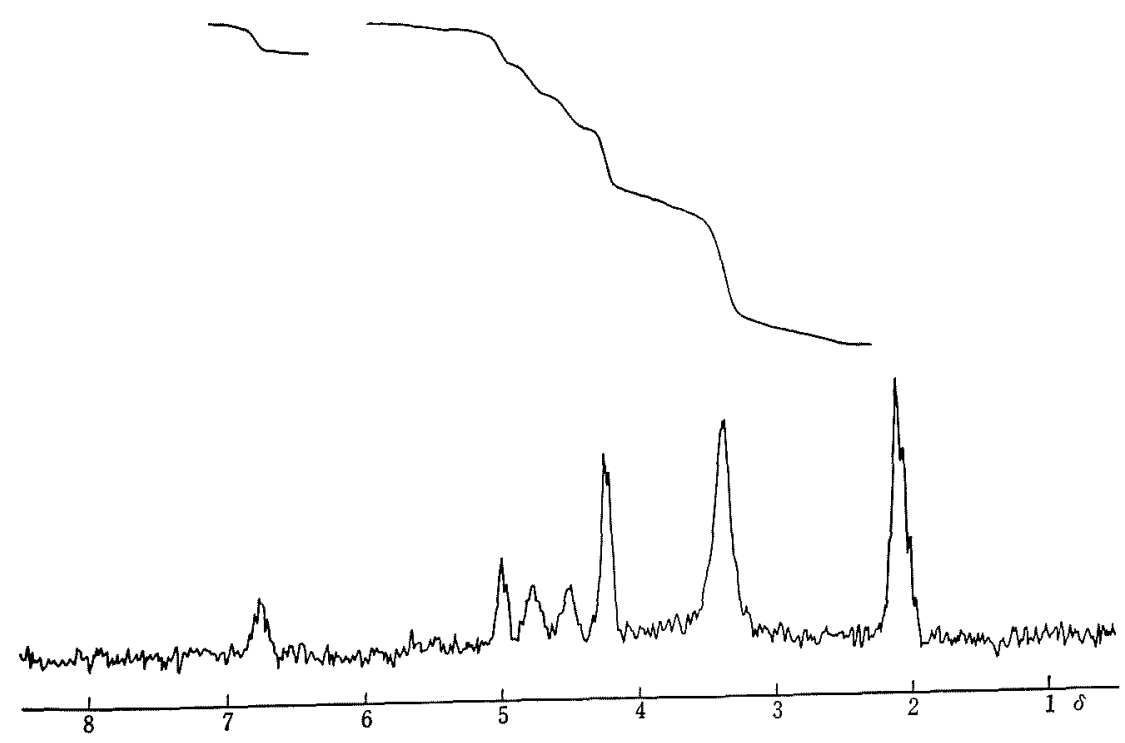

Chart 1b. PMR Spectrum of Compound $4\left(\left(\mathrm{CD}_{3}\right)_{2} \mathrm{CO}+\mathrm{D}_{2} \mathrm{O}\right)$. 


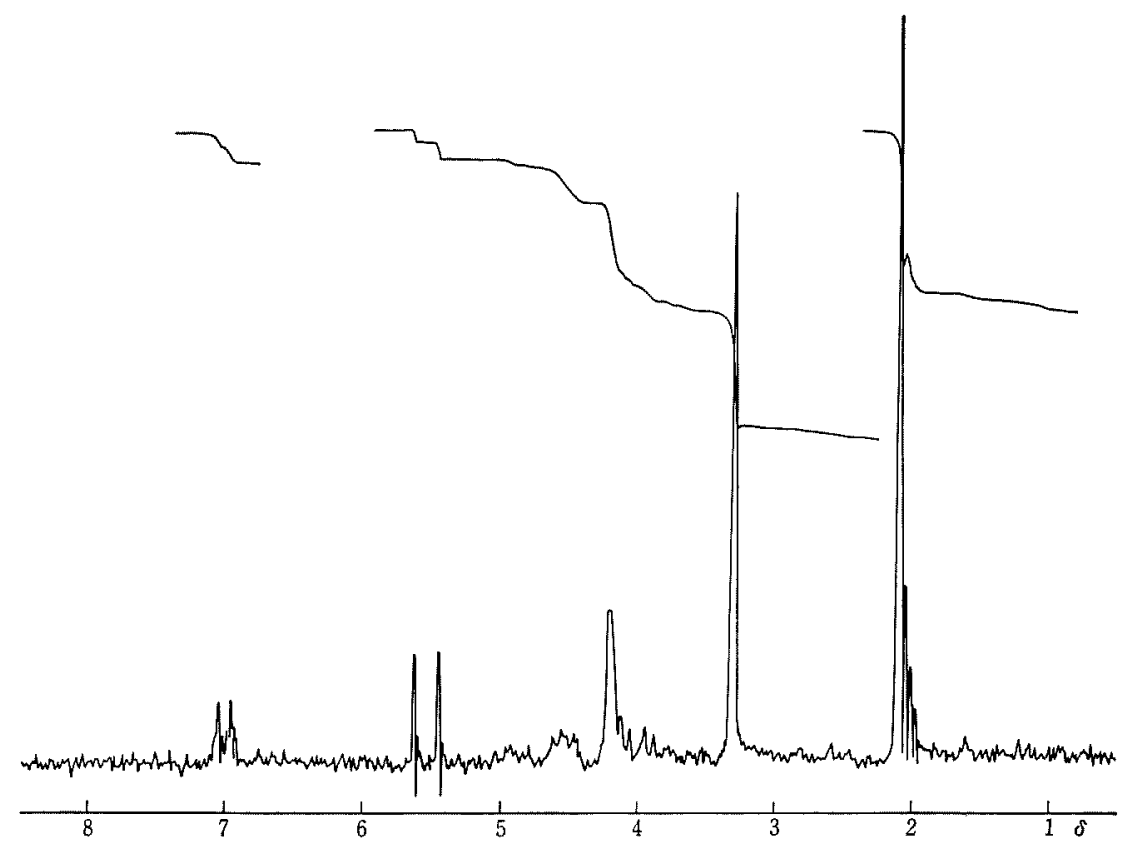

Chart 1c. PMR Spectrum of Compound $5\left(\left(\mathrm{CD}_{3}\right)_{2} \mathrm{CO}+\mathrm{D}_{2} \mathrm{O}\right)$.

without any other separating treatments. Recently it was further confirmed that 3 and $\mathbf{4}$ were detected in the solution in which epoxydon was treated under incubated condition. ${ }^{4}$ ) From these results it is concluded that 3 and 4 might be derived from epoxydon nonenzymatically, though the other compound 5 was obscure.

\section{EXPERIMENTAL}

\section{Isolation of chlorine containing compound $\mathbf{3}$ and $\mathbf{4}$}

The culture filtrates were treated as shown in Scheme 1. Thus the culture filtrate (15 liters) was added active charcoal-celite (2:1 v/v 6 liters) and the mixture was allowed to stand for $1 \mathrm{hr}$ at room temperature. The mixture was columned and the column was washed with 5 liters of desalted water and eluted with 10 liters of acetone. The eluate was concentrated in vacuo at $40^{\circ} \mathrm{C}$. The residue was mixed with $13 \mathrm{~g}$ of celite and the mixture was chromatographed on $160 \mathrm{~g}$ of silicic acid-celite $(1: 1 \mathrm{w} / \mathrm{w})$ column. The eluate with ethyl acetate-chloroform $(70: 30 \sim 80: 20 \mathrm{v} / \mathrm{v})$ gave a mixture of epoxydon and compound 3. Further elution with ethyl acetate-chloroform (90: 10 100: 0 $\mathrm{v} / \mathrm{v}$ ) gave compound 4 which was recrystallized from ethyl acetate to give $20 \mathrm{mg}$ of needles.

The mixture of epoxydon and compound 3 was chromatographed on $10 \mathrm{~g}$ of silicic acid and eluate with methanol-chloroform (5:95) gave pure epoxydon, compound 3 and inseparable mixture, which was further chromatographed to give pure 3. Combined crystalline material was recrystallized from ethanolchloroform to give $25 \mathrm{mg}$ of crystals.

\section{Isolation of compound 5}

The acetone eluate obtained from 15 liters of culture filtrate was acidified with small amount of acetic acid and concentrated in vacuo. The residue was mixed with $13 \mathrm{~g}$ of silicic acid and the slurry was chromatographed on $160 \mathrm{~g}$ of silicic acid-celite $(1: 1 \mathrm{w} / \mathrm{w})$. The column was eluted with ethyl acetate-chloroform (40: 60 100: $0 \mathrm{v} / \mathrm{v})$ and then with methanol-chloroform $(2: 98 \sim 5: 95 \mathrm{v} / \mathrm{v})$. The eluate was concentrated in vacuo to give a crystalline material which was recrystallized from ethanol to give $13 \mathrm{mg}$ of plates (Scheme 2).

Conversion of epoxydon to $6(S)$-chloro- $4(R), 5(R)$-dihydroxy-2-hydroxymethylcyclohex-2-en-1-one (3)

A solution of $215 \mathrm{mg}$ of epoxydon in $8 \mathrm{ml}$ of ethanol containing $0.4 \mathrm{ml}$ of concentrated hydrochloric acid was allowed to stand for $10 \mathrm{~min}$ at room temperature. The reaction mixture was extracted with ethyl acetate and the extract was washed with small amount of water. The solvent was evaporated in vacuo below $40^{\circ} \mathrm{C}$ and the residue was dissolved in methanolbenzene and evaporated in vacuo. After repeating this operation several time, benzene was added and 
precipitated powder $(227 \mathrm{mg})$ was recrystallized from ethyl acetate-chloroform to give triangular crystals.

\section{Formation of 6-chlorogentisyl alcohol from 4}

A solution of $24 \mathrm{mg}$ of fine crysytalline 4 in $1 \mathrm{ml}$ of methanol was allowed to stand for 4 weeks at room temperature. The reaction mixture was concentrated in vacuo below $40^{\circ} \mathrm{C}$. To the residue ethyl acetate was added and resultant crystalline material of 4 was removed by filtration. The filtrate was chromatographed on $2 \mathrm{~g}$ of silicic acid eluted with ethyl acetate-chloroform $(9: 1 \mathrm{v} / \mathrm{v})$ to give $0.5 \mathrm{mg}$ of crystalline 6-chlorogentisyl alcohol.

Conversion of $6(S)$-chloro-4(R), $5(R)$-dihydroxy-2-hydroxymethylcyclohex-2-en-1-one to $6(R)$-chloro- $4(R)$, $5(R)$-dihydroxy-2-hydroxymethylcyclohex-2-en-1-one

A solution of $60 \mathrm{mg}$ of 3 in $1.0 \mathrm{ml}$ of $5 \%$ sodium bicarbonate solution and $1.2 \mathrm{ml}$ of dioxane was allowed to stand for $4 \mathrm{~min}$ at room temperature. The reaction mixture was extracted with $80 \mathrm{ml}$ of ethyl acetate and extracts were washed with small amount of water then four times with $20 \mathrm{ml}$ of the same solvent. The combined extracts were dried over anhydrous sodium sulfate. The solvent was evaporated in vacuo to give $52 \mathrm{mg}$ of residue. A small amount of ethyl acetatechloroform $(9: 1 \mathrm{v} / \mathrm{v})$ was added to the residue and resultant crystalline material was filtered. The filtrate was chromatographed on $2 \mathrm{~g}$ of silica gel using ethyl acetate-chloroform $(9: 1 \mathrm{v} / \mathrm{v})$ as eluent to obtain crystaline compound. Combined crystalline material 4 was amount to $15 \mathrm{mg}$.

\section{REFERENCES}

1) S. Sakamura, H. Niki, Y. Obata, R. Sakai and T. Matsumoto, Agr. Biol. Chem., 33, 698 (1969); S. Sakamura, J. Ito and R. Sakai, ibid, 35, 105 (1971).

2) R. Sakai, R. Sato, H. Niki and S. Sakamura, Plant \& Cell Physiol., 11, 907 (1970).

3) A. Ichihara, K. Oda and S. Sakamura, Agr. Biol. Chem., 35, 445 (1971); A. Ichihara, K. Oda and S. Sakamura, Tetrahedron Letters, 1972, 5105; A. Ichihara, K. Oda and S. Sakamura, Agr. Biol. Chem., 38, 163 (1974).

4) K. Nabeta, A. Ichihara and S. Sakamura, Chem. Commun., 814 (1973); idem, Agr. Biol. Chem., 39, 409 (1975).

5) S. Sakamura, K. Nabeta, S. Yamada and A. Ichihara, Agr. Biol. Chem., 35, 1639 (1971). 